\title{
Dielectric Engineering to Suppress Cell-to-Cell Programming Voltage Interference in 3D NAND Flash Memory
}

\author{
Woo-Jin Jung and Jun-Young Park *(D) \\ School of Electronics Engineering, Chungbuk National University, Chungdae-ro 1, Chungbuk, \\ Cheongju 28644, Korea; jwjin@chungbuk.ac.kr \\ * Correspondence: junyoung@cbnu.ac.kr
}

check for updates

Citation: Jung, W.-J.; Park, J.-Y. Dielectric Engineering to Suppress Cell-to-Cell Programming Voltage Interference in 3D NAND Flash Memory. Micromachines 2021, 12, 1297. https://doi.org/10.3390/mi12111297

Academic Editors: Eun Kwang Lee and Jung Ho Yoon

Received: 30 August 2021

Accepted: 19 October 2021

Published: 22 October 2021

Publisher's Note: MDPI stays neutral with regard to jurisdictional claims in published maps and institutional affiliations.

Copyright: (C) 2021 by the authors. Licensee MDPI, Basel, Switzerland. This article is an open access article distributed under the terms and conditions of the Creative Commons Attribution (CC BY) license (https:/ / creativecommons.org/licenses/by/ $4.0 /)$.

\begin{abstract}
In contrast to conventional 2-dimensional (2D) NAND flash memory, in 3D NAND flash memory, cell-to-cell interference stemming from parasitic capacitance between the word-lines (WLs) is difficult to control because the number of WLs, achieved for better packing density, have been dramatically increased under limited height of NAND string. In this context, finding a novel approach based on dielectric engineering seems timely and applicable. This paper covers the voltage interference characteristics in 3D NAND with respect to dielectrics, then proposes an alternative cell structure to suppress such interference.
\end{abstract}

Keywords: dielectrics; flash memory; interference; cell-programming; vacuum dielectric; V-NAND

\section{Introduction}

NAND flash memory data storage has been developed for decades based on CMOS (complementary metal-oxide-semiconductor) technology [1]. NAND flash consists of memory cells and peripheral circuits. Binary data are 'programmed' in memory cells and the data state is 'read' with the aid of a logic controller that includes peripheral circuits. The data stored in memory cells can be sustained for approximately 10 years without power supply. Hence, NAND flash is categorized as non-volatile memory (NVM). Device structure of a memory cell is based on NMOS transistors, which inherently contain charge trap layers (CTL) such as $\mathrm{Si}_{3} \mathrm{~N}_{4}$ in the gate dielectric. When positive bias (typically higher than $10 \mathrm{~V}$ ) is applied to a gate electrode of a cell transistor to trigger 'programming', electrons are moved from the channel to the CTL by FN tunneling mechanism. In this context, the number of electrons stored in the CTL fundamentally represents the size of the binary data.

Device structure of the cell transistor has aggressively evolved for lower bit-cost. To elaborate, the bit-cost can be reduced by increasing cell packing density and so the size of the cell transistor has been scaled down over a long time. However, with scaling down of semiconductor devices, short-channel effects (SCEs) become worse. Therefore, the structure of the cell transistor has evolved from 2-dimensional (2D) planar FET to 3-dimensional (3D) gate-all-around (GAA) FET to suppress SCEs [2].

However, even though SCEs have been quite effectively controlled by the abovementioned evolution, other concerns have been raised, such as cell-to-cell interference [3-5], which is unwanted potential distribution during NAND operation. When high gate bias $\left(\mathrm{V}_{\mathrm{G}}\right)$ is applied to gate electrode so-called word-line $(\mathrm{WL})$, electrons are programmed not only in targeted cell transistors, but also in nearby cell transistors, which are not intended to be programmed.

The interference stems from isolation layers such as inter-layer dielectrics (ILD), which are located between each WL. As cell packing density increases under limited NAND string height and dry etching technology, the ILD becomes very thin. To avoid cell-to-cell interference without noticeable advances in fabrication processing, alternative techniques such as incremental step pulse programming (ISPP), multi-level cells (MLC), 
triple-level cells (TLC) and even quad-level cells (QLC) have been widely applied to mass production [6,7]. However, NAND flash beyond QLC is difficult to develop because of insufficient threshold voltage $\left(\mathrm{V}_{\mathrm{T}}\right)$ distribution. Hence, further advances via conventional techniques will be limited. In this context, guidelines for developing cell transistors to improve cell-to-cell interference should be proposed for better cell packing density of NAND flash devices, but such breakthrough research has been modest so far.

In this paper, dielectric engineering is newly proposed to suppress cell-to-cell interference in a 3D NAND flash. First, there is a discussion about unwanted potential distribution among WLs with respect to thickness, diameter and dielectric constant of dielectrics. Thereafter, a novel cell structure is proposed. Considering that demand for NAND flash has been dramatically increased during the COVID-19 pandemic, this research proposal seems very timely [8].

\section{Materials and Methods}

The 3D simulator COMSOL was utilized with an AC/DC module to investigate potential distribution in 3D NAND flash, as shown in Figure 1 [9]. Back-bone structure for the simulation was a terabit cell array transistor (TCAT) [10]. Five layers of ILDs, as well as WLs, were stacked on a silicon substrate. In addition, $\mathrm{SiO}_{2} / \mathrm{Si}_{3} \mathrm{~N}_{4} / \mathrm{Al}_{2} \mathrm{O}_{3}$ layers were included in a gate dielectric. A poly-Si channel $25 \mathrm{~nm}$ thick surrounded the macaroni filler, which was located at the middle of the hole, as shown in Figure 1c. Detailed information on the geometry and materials for simulations is provided in Table 1.
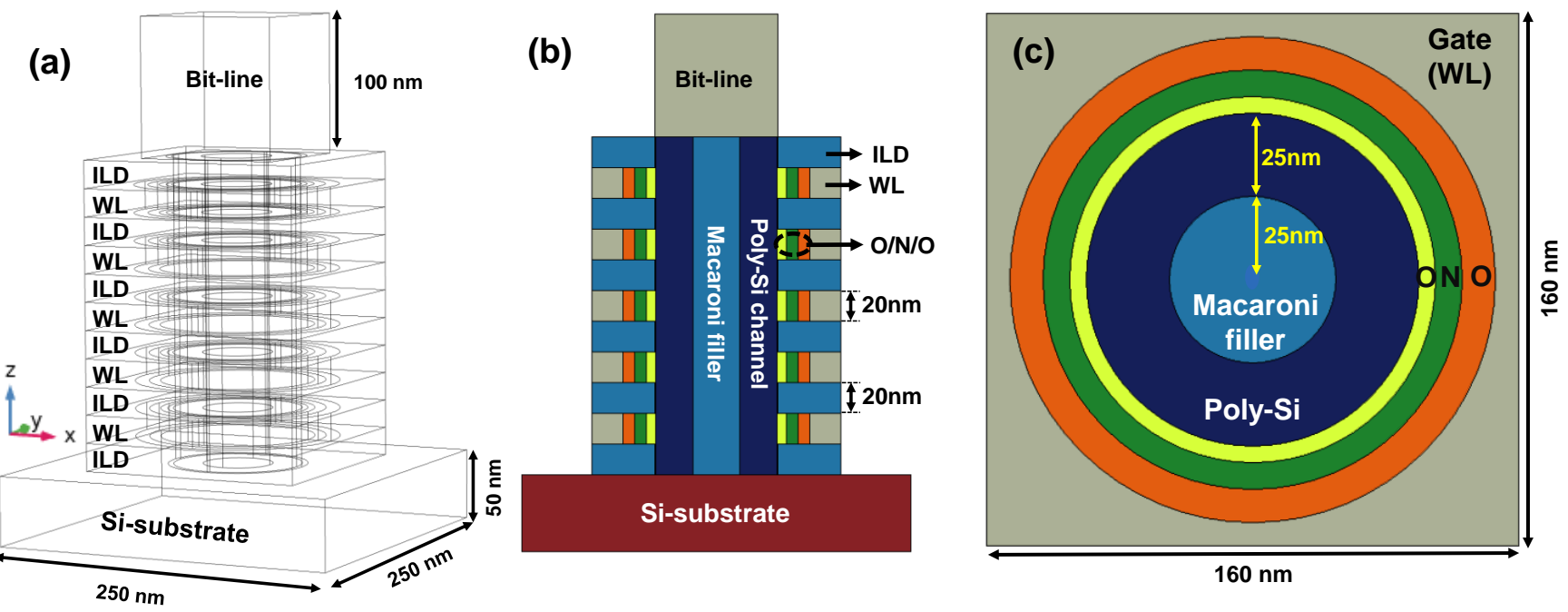

Figure 1. (a) Schematic geometry used for 3D simulations. (b) Cross-sectional view of structure cut along bit-line (BL) direction (xz-plane in Figure 1a) and (c) WL direction (xy-plane in Figure 1a). The O/N/O indicates a gate dielectric composed of $\mathrm{SiO}_{2}, \mathrm{Si}_{3} \mathrm{~N}_{4}$ and $\mathrm{SiO}_{2}$, respectively.

Table 1. Dimensions and material parameters for 3D simulations.

\begin{tabular}{ccccc}
\hline Geometry & Material & $\begin{array}{c}\text { Thickness } \\
\text { [nm] }\end{array}$ & Dielectric Constant & $\begin{array}{c}\text { Electrical } \\
\text { Conductivity [S/m] }\end{array}$ \\
\hline Word-line (WL) & $\mathrm{W}$ & 20 & 1 & $2 \times 10^{6}$ \\
Blocking oxide & $\mathrm{Al}_{2} \mathrm{O}_{3}$ & 10 & 5.7 & $10^{-11}$ \\
Charge trap layer & $\mathrm{Si}_{3} \mathrm{~N}_{4}$ & 8 & 9.7 & $10^{-11}$ \\
Tunneling oxide & $\mathrm{SiO}_{2}$ & 5 & 4.2 & $10^{-11}$ \\
Poly-Si channel & $\mathrm{Poly-Si}_{\text {Sild }}$ & 25 & 4.5 & $3 \times 10^{3}$ \\
Si-substrate & $\mathrm{Si}$ & 50 & 4.7 & $10^{4}$ \\
Macaroni filler & $\mathrm{SiO}_{2}$ & 50 & 1.2 & $10^{-11}$ \\
Bit-line (BL) contact & $\mathrm{W}$ & 100 & 4.2 & $2 \times 10^{6}$ \\
Inter-layer dielectric (ILD) & $\mathrm{SiO}_{2}$ & 20 & $10^{-11}$ \\
\hline
\end{tabular}




\section{Results}

To investigate the cell-to-cell interference during the 'programming' operation, $14 \mathrm{~V}$ DC bias $\left(\mathrm{V}_{\mathrm{PGM}}\right)$ was applied to one WL located in the middle of the NAND string, as shown in Figure 2a. During the simulation, both BL and Si-substrate were grounded. After saturation time of approximately $4 \mathrm{fs}$, the voltage applied to the WL was effectively transferred along the string, as shown in Figure 2b. Even though there are $20 \mathrm{~nm}$ ILD layers composed of $\mathrm{SiO}_{2}$ among the WLs, extracted voltage drop was approximately $5 \mathrm{~V}$ per each $\mathrm{WL}$, as shown in Figure 2c. This result indicates that cell-to-cell interference obviously exists during the cell 'programming' configuration in 3D NAND flash.
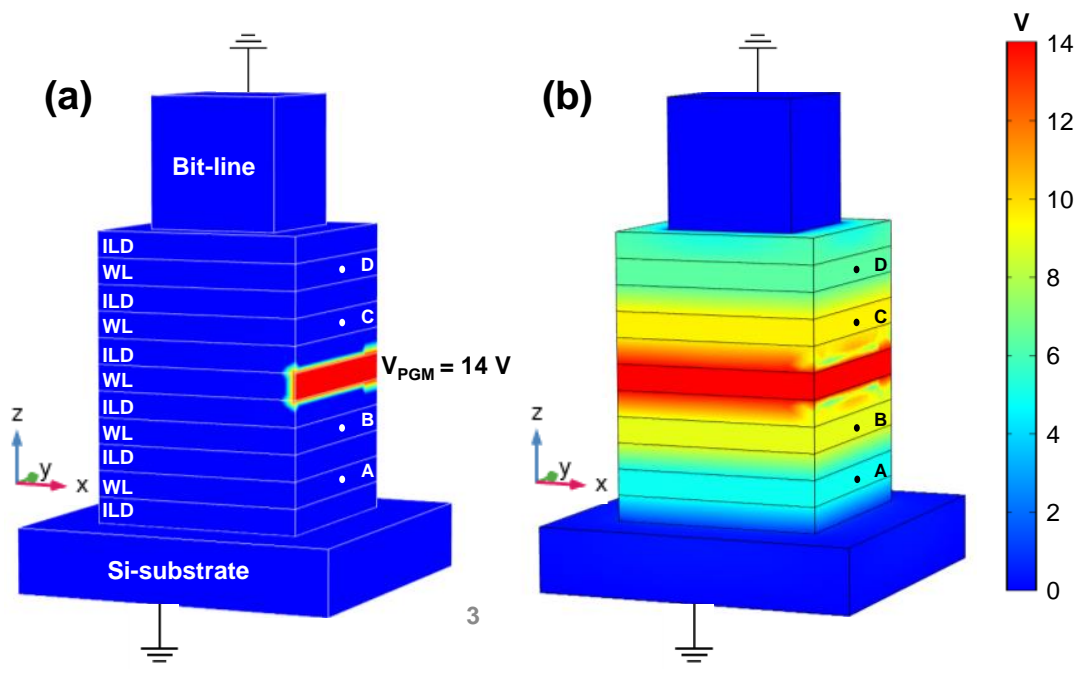

(c)

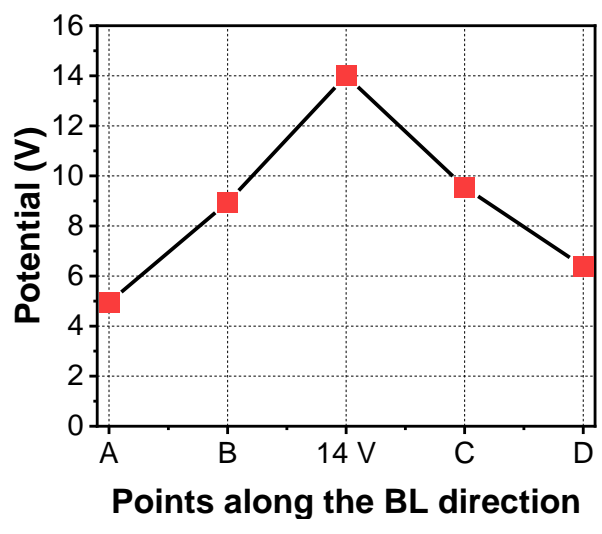

Figure 2. Simulated voltage distribution at (a) $t=0 \mathrm{~s}$ and (b) after saturation. (c) Extracted potentials at surface of WLs (points A to D).

Figure 3a shows cell-to-cell interference characteristic with various ILD thicknesses when $\mathrm{V}_{\mathrm{PGM}}$ of $14 \mathrm{~V}$ is applied to the 3rd WL only. As the ILD thickness decreases, cellto-cell interference increases with the slope of $91 \mathrm{mV} / \mathrm{nm}$ because of increased parasitic capacitance between the WLs. Considering that the ILD thickness becomes thinner as the number of stacks in the 3D NAND flash increases, it is obviously expected that the interference will become severe. Figure $3 b$ shows simulation results with various dielectric materials used as alternatives to the ILD. As the dielectric constant of the ILD decreases, the cell-to-cell interference can be improved because of reduced parasitic capacitance. Hence, applying a low- $k$ dielectric such as SiOC as the ILD would be preferred to improve the interference, rather than applying a conventional material such as $\mathrm{SiO}_{2}$ [11].

Figure 4 shows the simulation results of cell-to-cell interference for the macaroni filler. As the number of NAND layers increases, variability of the diameter of the macaroni filler in the NAND string also increases. Hence, it is noteworthy to observe the impact of the macaroni filler, as shown in Figure 4a. As the diameter of the macaroni filler decreases, the parasitic potential applied to nearby cells slightly decreased with the sensitivity of $0.34 \mathrm{mV} / \mathrm{nm}$. Hence, a narrower diameter macaroni filler is preferred to minimize cell-tocell interference. Considering the macaroni filler at low layers of NAND strings shows narrower diameter than filler at high layers, cell-to-cell interference at high layers might be more severe than in cells at low layers. However, there was no remarkable tendency in terms of dielectric constants (Figure 4b). 
(a)

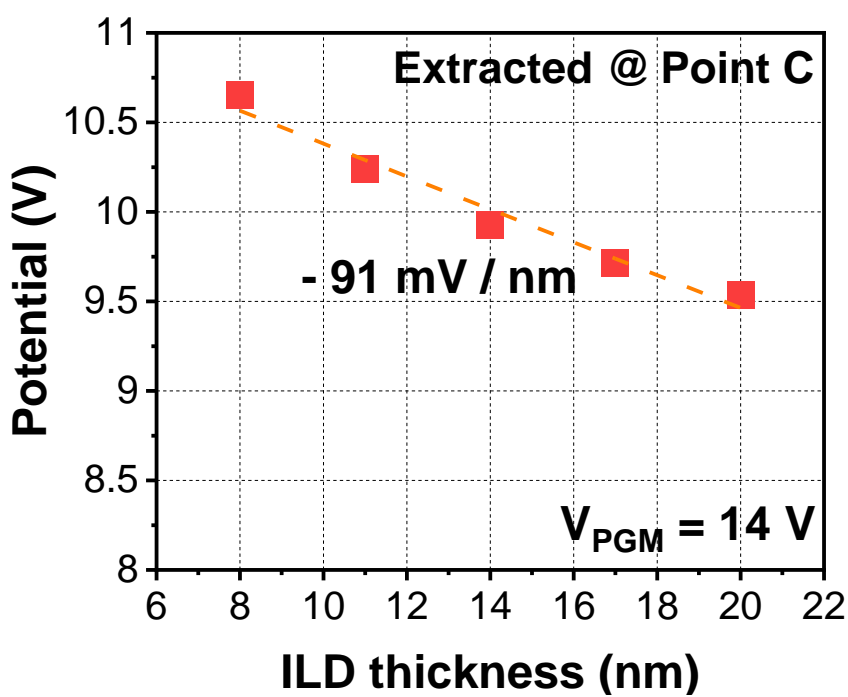

(b)

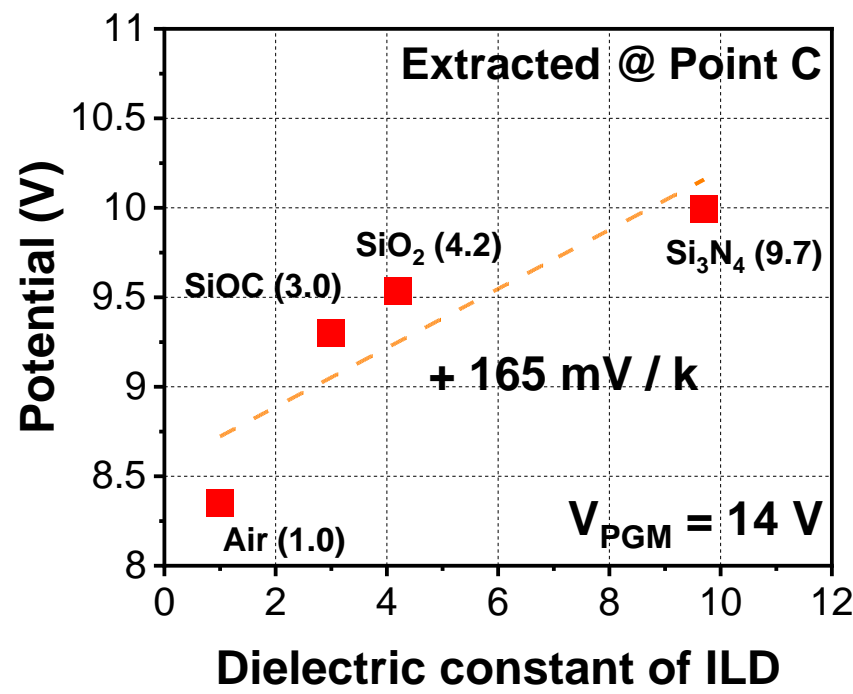

Figure 3. Extracted parasitic potential at nearby WL with various (a) thicknesses and (b) dielectric constants of ILD when $\mathrm{V}_{\mathrm{PGM}}$ of $14 \mathrm{~V}$ is applied to $3 \mathrm{rd} \mathrm{WL}$.

(a)

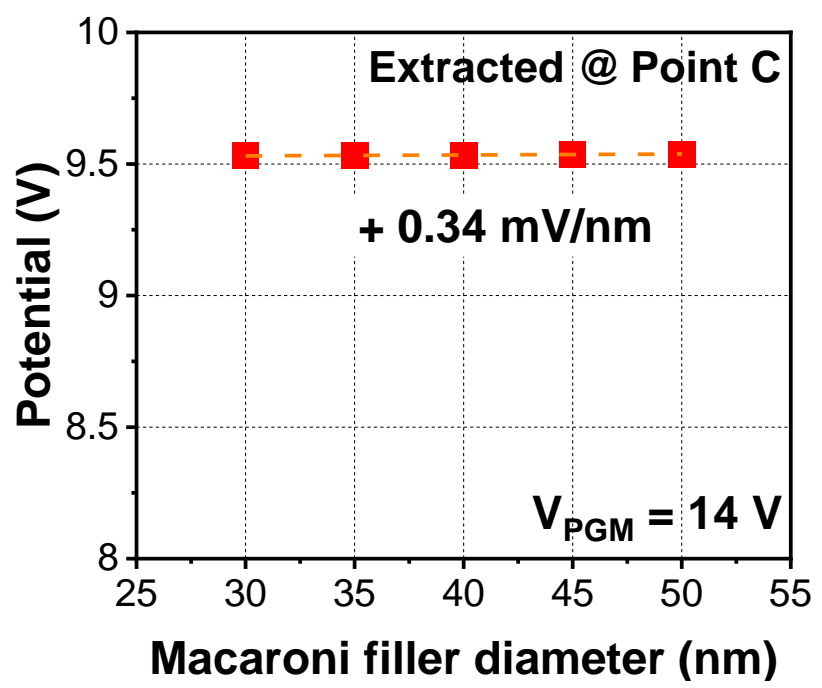

(b)

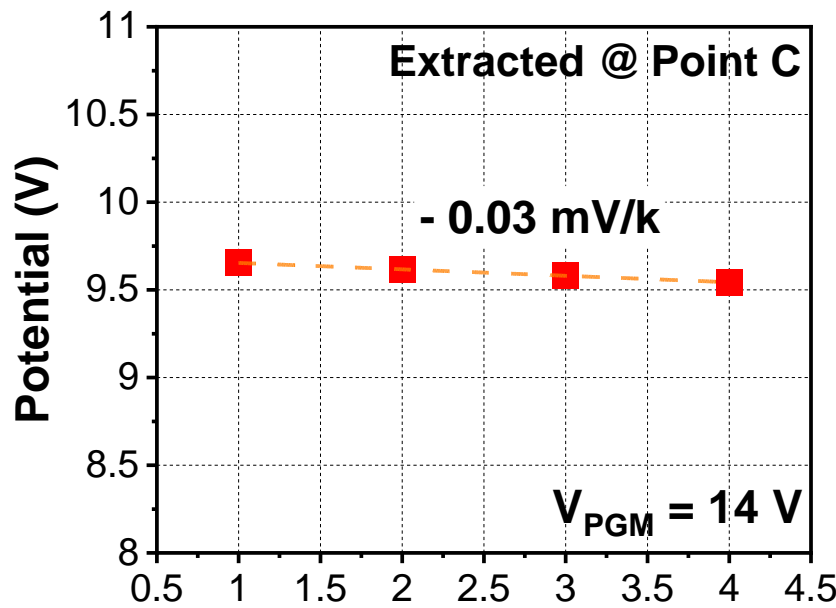

Dielectric constant of macaroni filler

Figure 4. Extracted parasitic potential with various (a) diameters and (b) dielectric constants of macaroni filler $\left(\mathrm{SiO}_{2}\right)$ when $\mathrm{V}_{\mathrm{PGM}}$ of $14 \mathrm{~V}$ is applied to $3 \mathrm{rd} \mathrm{WL}$.

Figure 5 shows simulation results with respect to WL (gate) thickness. As the number of stacks in the 3D NAND increases, cell-to-cell interference stemming from the ILD becomes severe, as mentioned above. However, contrary to the case of the ILD, this interference improved as the thickness of the WL decreased. When the WL thickness decreases (i.e., because of gate length scaling), the fringing field effect from the WL decreases and, hence, cell-to-cell interference can be improved [12]. In other words, considering that the WL thickness is being scaled down for higher packing density, additional gate engineering with respect to the interference is not required. 


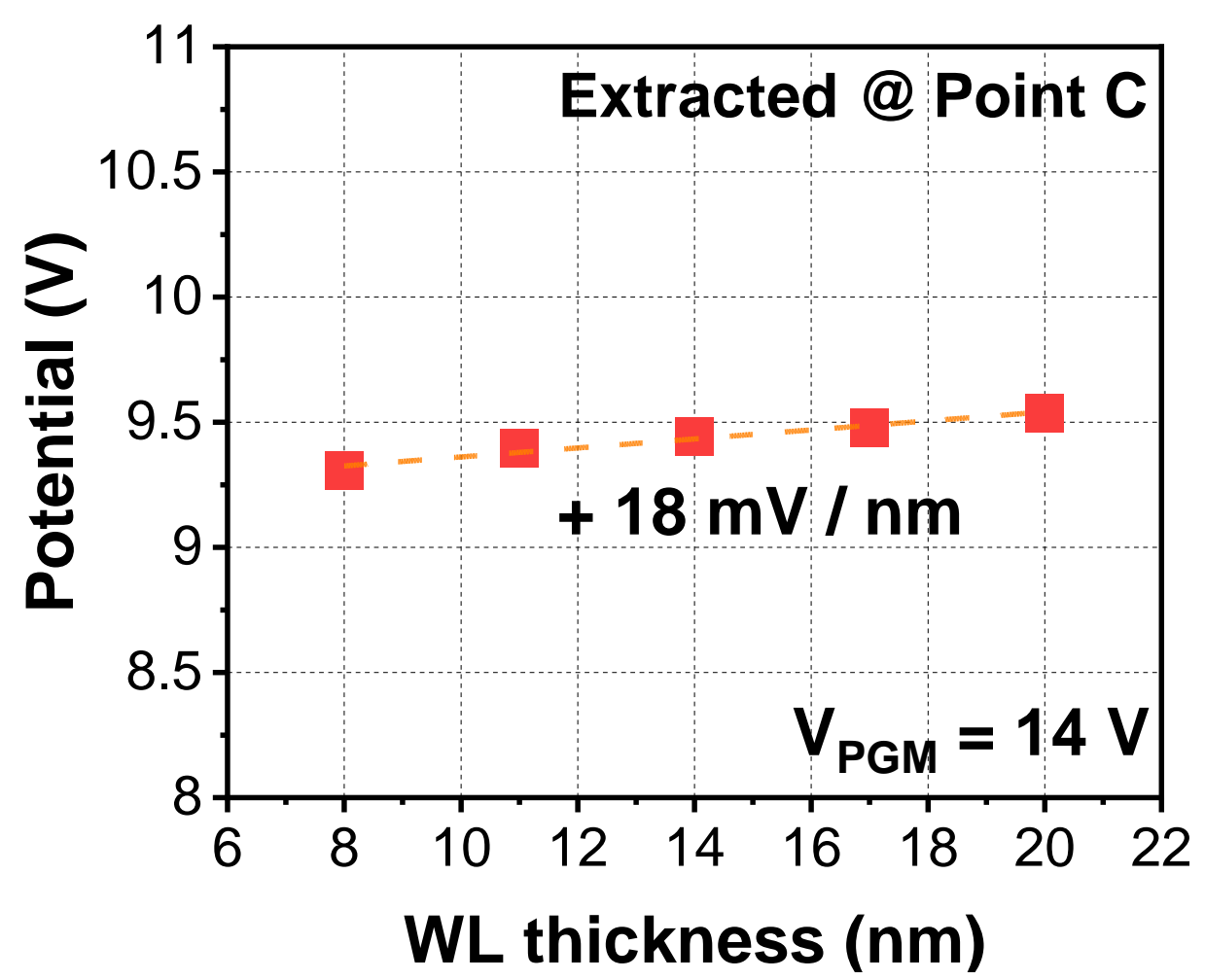

Figure 5. Extracted parasitic potential with various WL metal thicknesses.

Table 2 provides a summary of the cell-to-cell interferences and sensitivities for the different geometries and materials of dielectrics. It can be seen that the most significant dielectric to be modified to minimize the cell-to-cell interference is the ILD.

Table 2. Summary of cell-to-cell interference in terms of dielectrics in 3D NAND flash.

\begin{tabular}{cccc}
\hline Geometry & Material & Thickness & Dielectric Constant \\
\hline Inter-layer dielectric (ILD) & $\mathrm{SiO}_{2}$ & $-91 \mathrm{mV} / \mathrm{nm}$ & $+165 \mathrm{mV} / \mathrm{k}$ \\
Macaroni filler & $\mathrm{SiO}_{2}$ & $+0.34 \mathrm{mV} / \mathrm{nm}$ & $-0.03 \mathrm{mV} / \mathrm{k}$ \\
Word-line (WL) & $\mathrm{W}$ & $+18 \mathrm{mV} / \mathrm{nm}$ & - \\
\hline
\end{tabular}

In this context, we newly propose a 3D NAND structure to minimize the cell-to-cell interference, as shown in Figure 6. A vacuum cavity was defined inside the ILD and conventional inorganic dielectric material such as $\mathrm{SiO}_{2}$ surrounded the cavity [13-17].

Figure 7 shows the fabrication process flow of the proposed 3D NAND flash. The multi layers composed of $\mathrm{SiO}_{2}$ / sacrificial polymer layer $/ \mathrm{SiO}_{2}$ and $\mathrm{Si}_{3} \mathrm{~N}_{4}$, were deposited iteratively on an Si-substrate, as shown in Figure 7a. It should be noted that such sacrificial layers can decompose during heat treatment [18,19]. After dry etching, poly-Si was deposited on the sidewall; thereafter, $\mathrm{SiO}_{2}$ was filled in as macaroni filler (Figure $7 \mathrm{~b}$ ). Etching of the top side and heavy doping of poly-Si deposition were performed for drain region definition (not shown). Then, dry etching, sacrificial $\mathrm{Si}_{3} \mathrm{~N}_{4}$ removal and tunneling oxide deposition were sequentially performed (Figure 7c-e). Thermal annealing to remove the sacrificial polymer layer was performed to form a vacuum dielectric inside the ILD (Figure 7f). Then, $\mathrm{Si}_{3} \mathrm{~N}_{4} \mathrm{CTL}, \mathrm{Al}_{2} \mathrm{O}_{3}$ blocking oxide and metal gate were deposited (Figure 7g). Finally, the ILD was filled between the nodes (not shown). 
(a)

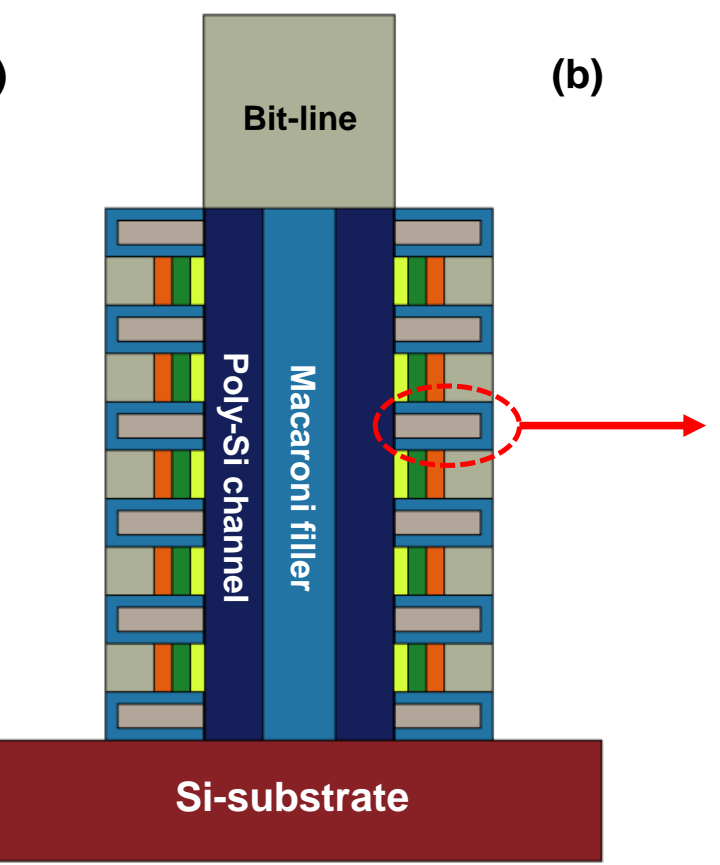

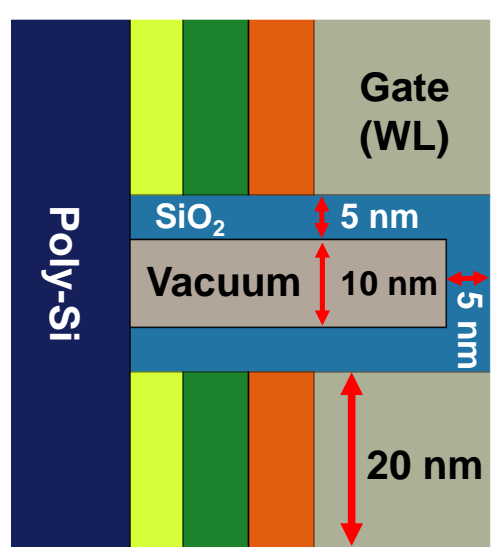

Gate

WL)

Figure 6. (a) Schematic of proposed 3D NAND flash string with vacuum dielectric. (b) Magnified image of cells.

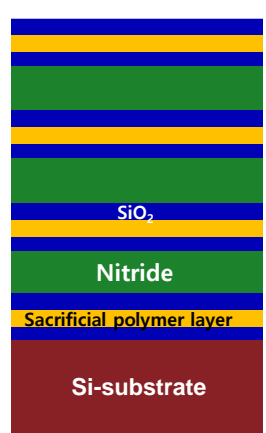

(a)

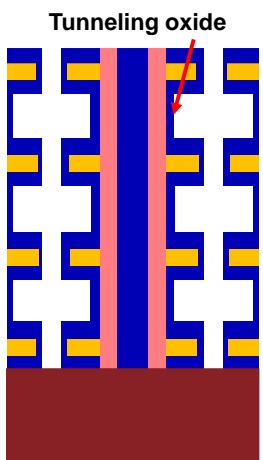

(e)

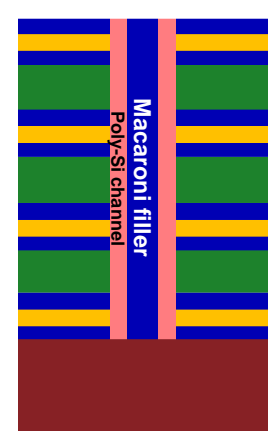

(b)

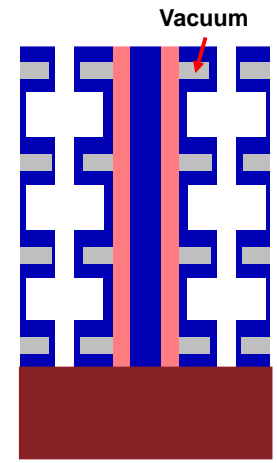

(f)

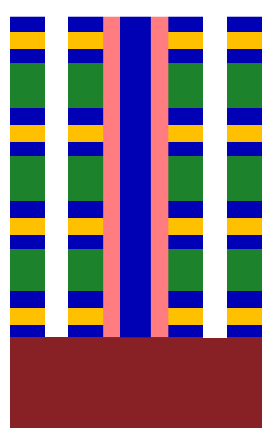

(c)

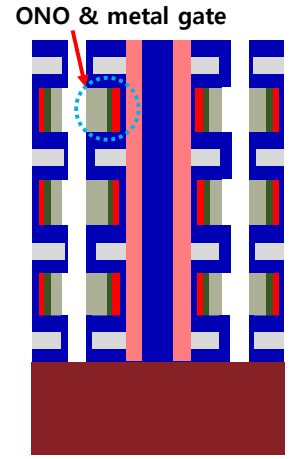

(g)

Figure 7. Fabrication process flow of proposed 3D NAND structure containing vacuum dielectric. (a) Iterative deposition of oxide, sacrificial polymer, oxide, and silicon nitride layer. (b) Dry etching of hole, deposition of poly-silicon channel, and fills the hole by oxide. (c,d) Dry etching and selective etching of silicon nitride layer. (e,f) After deposition of tunneling oxide, the polymer layer is thermally decomposed. (g) Deposition of charge trap layer, blocking oxide, metal gate, and finally fills inter layer dielectric. 
Figure 8 shows the extracted parasitic potential with various thicknesses of liner composed of $\mathrm{SiO}_{2}$. Dielectric constant of vacuum during the simulation was assumed to be 1.0. As the thickness of the liner decreased, the volume of the vacuum increased. The cell-to-cell interference can be improved owing to the lowered parasitic capacitance.

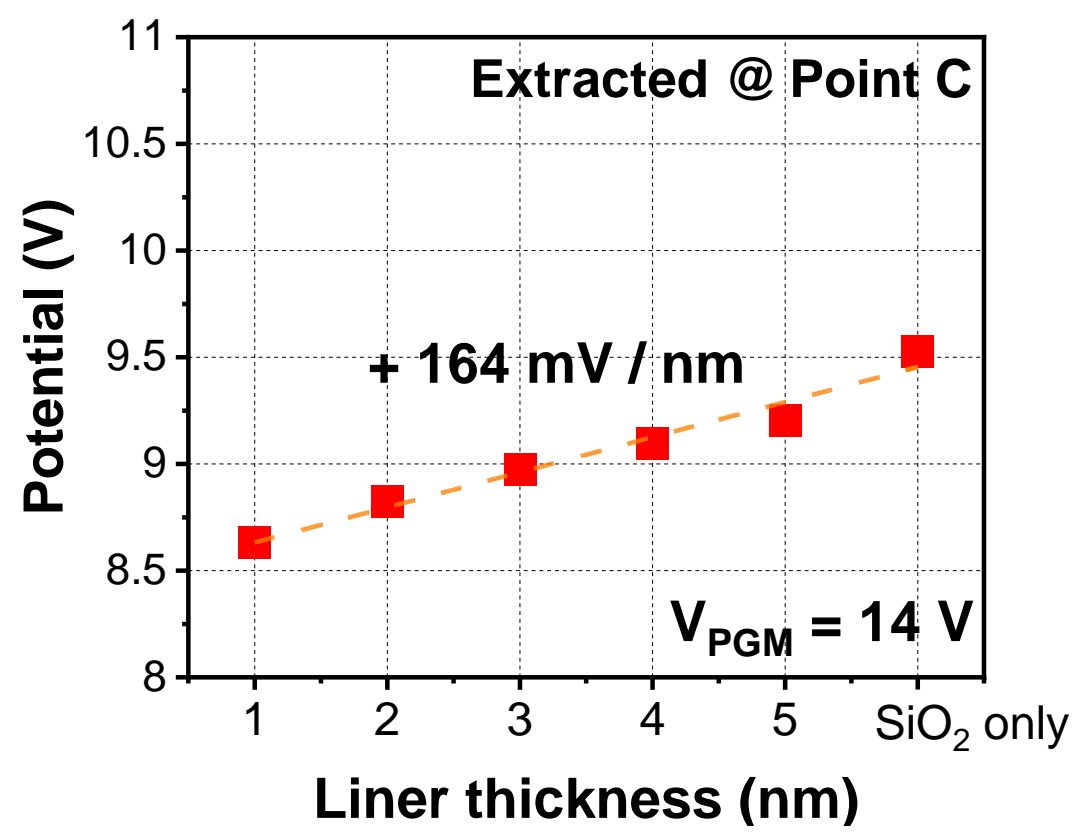

Figure 8. Simulated parasitic potential with various thicknesses of liner surrounding the vacuum cavity.

\section{Conclusions}

Simulation studies have been performed to suppress cell-to-cell interference in 3D NAND flash memory during program operation. Voltage interference among the cells was discussed with respect to dielectrics such as inter-layer dielectric (ILD) and macaroni filler. Then, several sensitivities that impact the cell-to-cell interference were extracted and compared. It was found that the most significant dielectric to determine the interference was the ILD. As a result, a novel 3D NAND structure containing a vacuum dielectric inside of the ILD was newly proposed. The cell-to-cell program interference was reduced by aid of the proposed device structure.

Author Contributions: For J.-Y.P. conceived this project and designed all the experiments. W.-J.J. conducted all the simulations and wrote this paper. All authors have read and agreed to the published version of the manuscript.

Funding: This work was supported by the National Research Foundation (NRF) of Korea grant funded by the Korea government (MSIT) (No. 2020M3H2A1076786 and 2021R1F1A1049456).

Institutional Review Board Statement: Not applicable.

Informed Consent Statement: Not applicable.

Acknowledgments: The authors appreciate to D.-H. Yun for his valuable comments.

Conflicts of Interest: The authors declare no conflict of interest.

\section{References}

1. Monzio Compagnoni, C.; Goda, A.; Spinelli, A.S.; Feeley, P.; Lacaita, A.L.; Visconti, A. Reviewing the Evolution of the NAND Flash Technology. Proceed. IEEE 2017, 105, 1609-1633. [CrossRef]

2. Spinelli, A.S.; Malavena, G.; Lacaita, A.L.; Monzio Compagnoni, C. Random Telegraph Noise in 3D NAND Flash Memories. Micromachines 2021, 12, 703. [CrossRef] [PubMed]

3. Yi, S.-I.; Kim, J. Novel Program Scheme of Vertical NAND Flash Memory for Reduction of Z-Interference. Micromachines 2021, 12, 584. [CrossRef] [PubMed] 
4. Lee, J.-D.; Hur, S.-H.; Choi, J.-D. Effects of floating-gate interference on NAND flash memory cell operation. IEEE Electron Device Lett. 2002, 23, 264-266. [CrossRef]

5. Cai, Y.; Mutlu, O.; Haratsch, E.F.; Mai, K. Program interference in MLC NAND flash memory: Characterization, modeling, and mitigation. In Proceedings of the IEEE 31st International Conference on Computer Design (ICCD), Asheville, NC, USA, 6-9 October 2013; pp. 123-130. [CrossRef]

6. Cai, Y.; Haratsch, E.F.; Mutlu, O.; Mai, K. Threshold voltage distribution in MLC NAND flash memory: Characterization, analysis, and modeling. In Proceedings of the 2013 Design, Automation \& Test in Europe Conference \& Exhibition (DATE), Grenoble, France, 18-22 March 2013; pp. 1285-1290. [CrossRef]

7. Lue, H.-T.; Hsu, T.-H.; Wang, S.-Y.; Lai, E.-K.; Hsieh, K.-Y.; Liu, R.; Lu, C.-Y. Study of Incremental Step Pulse Programming (ISPP) and STI Edge Effect of BE-SONOS NAND Flash. In Proceedings of the 2008 IEEE International Reliability Physics Symposium, Phoenix, AZ, USA, 27 April-1 May 2008; pp. 693-694.

8. Nguyen, T.; Duong Bang, D.; Wolff, A. 2019 Novel Coronavirus Disease (COVID-19): Paving the Road for Rapid Detection and Point-of-Care Diagnostics. Micromachines 2020, 11, 306. [CrossRef] [PubMed]

9. COMSOL Multiphysics, version 5.4. In The AC/DC Module User's Guide; COMSOL: Burlington, MA, USA, $2019 ;$ pp. 75-84.

10. Jang, J.-H.; Kim, H.-S.; Cho, W.-S.; Cho, H.-S.; Kim, J.-H.; Shim, S.-I.; Jang, Y.-G.; Jeong, J.-H.; Son, B.-K.; Kim, D.-W.; et al. Vertical cell array using TCAT(Terabit Cell Array Transistor) technology for ultra high density NAND flash memory. In Proceedings of the 2009 Symposium on VLSI Technology, Kyoto, Japan, 15-17 June 2009; pp. 192-193.

11. Kim, H.J.; Shao, Q.; Kim, Y.-H. Characterization of low-dielectric-constant SiOC thin films deposited by PECVD for interlayer dielectrics of multilevel interconnection. Surf. Coat. Technol. 2003, 171, 1-3. [CrossRef]

12. Shah, K.; Singh, J.; Zayegh, A. Modelling and analysis of fringing and metal thickness effects in MEMS parallel plate capacitors. Microelectron. Des. Technol. Packag. II 2006, 6035, 603511. [CrossRef]

13. Pundir, Y.P.; Bischt, A.; Saha, R.; Pal, P.K. Air-spacers as analog-performance booster for 5 nm-node N-channel nanosheet transistor. Semicond. Sci. Technol. 2021, 36, 9. [CrossRef]

14. Sachid, A.B.; Huang, Y.-M.; Chen, Y.-J.; Chen, C.-C.; Lu, D.D.; Chen, M.-C.; Hu, C. FinFET With Encased Air-Gap Spacers for High-Performance and Low-Energy Circuits. IEEE Electron Device Lett. 2017, 38, 16-19. [CrossRef]

15. Togo, M.; Tanabe, A.; Furukawa, A.; Tokunaga, K.; Hashimoto, T. A gate-side air-gap structure (GAS) to reduce the parasitic capacitance in MOSFETs. In Proceedings of the 1996 Symposium on VLSI Technology. Digest of Technical Papers, Honolulu, HI, USA, 11-13 June 1996; pp. 38-39. [CrossRef]

16. Cheng, K.; Park, C.; Yeung, C.; Nguyen, S.; Zhang, J.; Miao, X.; Wang, M.; Mehta, S.; Li, J.; Surisetty, C.; et al. Air spacer for 10 nm FinFET CMOS and beyond. In Proceedings of the 2016 IEEE International Electron Devices Meeting (IEDM), San Francisco, CA, USA, 3-7 December 2016; pp. 17.1.1-17.1.4. [CrossRef]

17. Park, J.-M.; Hwang, Y.-S.; Kim, S.-W.; Han, S.-Y.; Park, J.-S.; Kim, J.; Seo, J.-W.; Kim, B.-S.; Shin, S.-H.; Cho, C.-H.; et al. 20 nm DRAM: A new beginning of another revolution. In Proceedings of the 2015 IEEE International Electron Devices Meeting (IEDM), Washington, DC, USA, 7-9 December 2015; p. 26. [CrossRef]

18. Chan, K.; Gleason, K.-K. Air-gap fabrication using a sacrificial polymeric thin film synthesized via initiated chemical vapor deposition. J. Electrochem. Soc. 2006, 153, 4. [CrossRef]

19. Park, S.-H.; Allen, S.A.B.; Kohl, P.A. Air-Gaps for High-Performance On-Chip Interconnect Part II: Modeling, Fabrication, and Characterization. J. Electron. Mater. 2008, 37, 1534-1546. [CrossRef] 